\title{
ACQUiSiTION OF OPERATIONS CAPABILITY: A Model AND TeSt ACross U.S. AND European Firms
}

\author{
Keah Choon Tan* \\ University of Nevada Las Vegas \\ College of Business \\ Department of Management \\ 4505 Maryland Parkway, Box 456009 \\ Las Vegas, NV 89154-6009 \\ Tel: (702) 895-3873 \\ kctan@unlv.edu \\ Vijay R. Kannan \\ Department of Business Administration \\ Utah State University \\ Logan, UT 84322-3510 \\ Tel/Fax: (435) 797-7212/2634 \\ vkannan@b202.usu.edu \\ Jayanth Jayaram \\ University of South Carolina \\ Moore School of Business \\ Department of Management Science \\ University of South Carolina \\ 1705 College Street \\ Columbia, SC 29208 \\ jayaram@moore.sc.edu \\ Ram Narasimhan \\ Michigan State University \\ Department of Marketing and Logistics \\ The Eli Broad Graduate School of Management \\ East Lansing, MI 48824-1122 \\ Tel: (517) 349-3276 \\ narasimh@msu.edu
}

December 17, 2002

[Prepared for submission to IJPR]

(Word Count: 5764)

NoTe

* Corresponding author. 


\title{
ACQUiSITION OF OPERATIONS CAPABILITY: A Model AND TeSt ACross U.S. AND EUROPEAN FirmS
}

\begin{abstract}
In this paper, a three-factor model of operations capability is presented which, unlike previous studies that view capability as an outcome, examines the drivers of capability acquisition. The model proposes that capability acquisition is a function of an organization's commitment to the principles of quality management, just-in-time practices, and effective new product development processes. Furthermore, the paper proposes that these underlying facets of capability acquisition are common across geographic boundaries. The model is tested using data drawn from U.S. and European companies. Results not only provide support for the three-factor model, but also for the invariance of the model and its underlying components between U.S. and European firms.
\end{abstract}

Subject Areas: Just-In-Time, Quality, Product Development, Empirical Research, Invariant Factorial Structure Analysis 


\section{Introduction}

The notion that operations plays a significant role in and is at the forefront of corporate strategy has attracted considerable attention, largely due to the success of companies such as Toyota, Motorola, 3M and Hewlett Packard. These companies have embraced several thematic managerial prescriptions such as Total Quality Management (TQM), Just-In-Time (JIT), Business Process Reengineering, and Concurrent Engineering. While the performance implications of pursuing these themes have not been consistent or universal, the notion that they have prompted managerial action to augment the operations capabilities of companies is widely accepted (Hammer and Champy, 1993, Hayes et al., 1988, Schonberger, 1986). The generation, sustainability, and integration of operations capabilities across the value chain has generated a rapidly growing research stream within the operations strategy literature. The theoretical impetus for this stream lies in the resource-based view of the firm (Barney, 1991, Grant, 1991, Peteraf, 1993). This argues that successful firms acquire and control rent-yielding resources that can result in an inimitable source of competitive advantage. The inimitability is attributable to the fact that process knowledge, through which resources are translated into capabilities, is less transparent to other firms. Toyota, for example, is credited with having the advantage of the lowest cost per vehicle in the automotive OEM industry. The company's early emphasis on waste elimination through JIT and TQM strategies has been a large contributor to this low cost advantage. Several competitors have attempted to replicate Toyota's success, but with only varying degrees of success.

The importance of the operations function as a supporter of strategic objectives and driver of business performance is well documented. Evidence based on the resource-based view of the firm suggests that acquiring and controlling tangible (e.g., equipment) and intangible (e.g., 
process knowledge) resources can create a sustainable competitive advantage over competitors (Amit and Shoemaker, 1993, Barney, 1991, Grant, 1991). The manufacturing strategy literature contains numerous references to the importance of developing and nurturing manufacturing capabilities as a means of achieving long-term success (e.g., Hayes and Pisano, 1996, Roth and Miller, 1992). Indeed, empirical evidence supports the notion that a relationship exists between manufacturing capabilities and the ability of a firm to meet its strategic objectives (Cleveland, et al., 1989, Roth and Miller, 1992, Vickery et al., 1993, Droge et al., 1994).

While the relationship between manufacturing capabilities and business performance has been well documented, it has been based on the assumption that capability is synonymous with competitive goals and priorities. Both the production competence and manufacturing capability literature view capability from an outcome perspective, identifying performance indicators that signify the presence or otherwise of a capability. Moreover, the empirical evidence is drawn mostly from studies of U.S. firms. The purpose of this study is to add to the discussion of capabilities in two ways. The first is to propose and test a model of capability acquisition. The model views capability from an input perspective, examining actions and decisions within the direct and interface responsibility of the operations function, which enable it to support strategic goals dictated by top management. The second purpose is to identify whether this model and its underlying constructs are equivalent across operating environments, specifically the U.S. and Europe. Equivalence is frequently referred to as 'measurement invariance', because if measures are not comparable (i.e., on the same measurement scale or measuring the same construct) across groups, mean levels or patterns of correlations of the measure with external variables may be context specific. This may suggest that conclusions drawn from the measurements may be misleading (Reise et al., 1993). The assessment of cross-cultural equivalence of a psychometric 
measure plays a crucial role in establishing construct validity and therefore the appropriateness of using a particular measure in cross-national research (Cronbach and Meehl, 1955).

\section{Operations Capability}

It is generally accepted that a linkage exists among corporate level decisions and functional level decisions. It is also accepted that the effectiveness of decision-making is evaluated on the criteria of value creation. However, the process of value creation is not easily understood in many firms in a competitive environment. Research has shown that firms operating in the same market segment using similar functional strategies can have dramatically different levels of performance (Cool and Schendel, 1988). Differences in performance can result from differences in functional level competencies, more proficient firms being able to better manage the development of distinctive competencies and thus achieve higher levels of performance (Lawless et al., 1989).

From an operations perspective, two questions that arise are what specific capabilities translate into high degrees of value creation, and how are these capabilities acquired. The manufacturing strategy literature provides ample evidence in response to the first question. Summarizing the pertinent literature, Leong et al., (1990) identified four manufacturing capabilities, or dimensions along which an organization must be able to compete, widely accepted as being relevant to an organization's success: quality, delivery, cost, and flexibility. Several empirical studies support the contention that these capabilities do in fact represent the means by which the manufacturing function supports superior performance (e.g. De Meyer et al., 1989, Ferdows and De Meyer 1990, Noble, 1995). Whether an organization is able to simultaneously demonstrate capability in all areas is however uncertain. Proponents of the 'tradeoff' theory of capability development suggest that due to the inherent conflicts in attaining 
capabilities, organizations must make tradeoffs between them. While there is empirical support for this proposition (Safizadeh et al., 2000), support also exists for the counter position that a company can demonstrate superior capabilities in all areas (Roth and Miller, 1992). Evidence also exists to support the 'cumulative' or 'sandstone' theory of capability development (Ferdows and De Meyer, 1990), that certain capabilities must be developed before others can be (Roth and Miller, 1992).

The relationship between capability and value creation has also been well documented. Roth and Miller (1992) demonstrated a relationship between a firm's average capability in five areas (quality, delivery, market scope, flexibility, and price) and several measures of business performance including sales revenue and growth, market share, and return on assets. With the exception of quality, high performing firms exhibited superior capability in all areas compared to low performing firms. Cleveland et al. (1989) identified nine areas of operations that can positively or negatively impact the attainment of corporate objectives. These areas, for example quality performance, delivery performance, and process technology, were incorporated into a measure of whether operations is effective in furthering corporate objectives, taking into account whether a firm is strong, neutral or weak on each of the dimensions, and the relative importance of the dimension in achieving strategic objectives. The authors demonstrated a linear relationship between this index of production competence and performance, measured in terms of market share, growth rate, and return in assets relative to the industry. Vickery et al., (1993) developed a similar but more comprehensive measure of production competence. They identified a total of thirty-one items that were either competitive goals, reflected value added, or evaluated service to customers. The items used included new product introduction, product development cycle time, production lead-time, delivery speed, and low cost distribution. These items were used to 
develop a measure of production competence that takes into account the strategic importance of each item to the firm, the extent to which manufacturing has responsibility for the item, and a firm's performance on the item relative to that of its major competitors. They also demonstrated a significant relationship between measures of production competence and firm performance. In one of the few operations strategy studies to examine measurement invariance, Narasimhan and Jayaram (1998) examined patterns of causal relationships between capability enablers, including supply management, process improvement and information systems, and performance, measured in terms of manufacturing goal achievement and customer responsiveness in North American, European, and Pan Pacific firms. They found that significant regional differences exist in how enablers impacted performance.

While the question of what capabilities impact performance has been addressed in depth, the question of capability acquisition has received less attention. Roth and Miller (1992) identified three areas relevant to the development of manufacturing capabilities: resource improvements, which include development of an effective manufacturing infrastructure, training, maintenance, and quality management programs; which include the use of statistical process control and vendor quality management, and the use of advanced manufacturing technologies. De Meyer et al. (1989) also raised the issue of action plans in support of manufacturing capabilities. As part of one of few cross border studies on manufacturing strategy, they also identified the use of quality programs as a key driver of capability acquisition in the U.S. context, as well as the use of effective production and inventory control systems and improvements in new product development processes.

From the preceding discussion, it is clear that while manufacturing capability has been examined extensively from an output perspective, the drivers and process of capability 
acquisition have been largely overlooked. It is important however to examine capability from an input as well as an output perspective. The argument presented here is that capability is a mediating outcome of a resource deployment process intended to yield competitive advantages such as low cost, high flexibility and short lead times. For our purposes, resource deployment process is defined as a commitment to action programs or 'strategic initiatives' having a common higher order goal. For example, action programs such as preventive maintenance, lot size reduction and set up time reduction collectively constitute the strategic initiative of just-in-time which has a higher order goal of waste minimization. Implementation of the initiative leads to reductions in cost, and improvements in quality, delivery and flexibility, thereby generating capability. Our operationalization of capability suggests a concomitant build up of sources of distinctive advantage as the resource deployment process unfolds, and that successful implementation of strategic initiatives yields capabilities that result in superior performance. A distinction is thus made between the process of capability acquisition (focus of our paper) and the consequences of capability acquisition (focus of prior research). The following section draws on the literature to identify the drivers of the underlying operations capabilities of quality, delivery, cost, and flexibility, and proposes a model of capability acquisition.

\section{Elements of Operations Capability}

\subsection{New Product Design and Development Capability (NPDD, $\left.\xi_{1}\right)$}

As global competition intensifies and product life cycles shrink, effectively managing new product design and development is becoming a major focus of many organizations, especially for market leaders competing on rapid product development. These organizations remain competitive by bringing quality products to market ahead of the competition. However, new product development is inherently costly and risky, particularly when new technology is 
involved. To satisfy changing customer demands, savvy organizations participate in collaborative product development efforts to reduce the costs and risks of product development and to take advantage of market opportunities and technical expertise (Littler et al., 1995, Ragatz et al., 1997). The literature also indicates that firms are engaging in collaborative development relationships with their suppliers, viewing the supplier as a virtual extension of their own firm (Mason, 1996, Copacino, 1996, Tan, 2001).

Griffin (1997), and Zirger and Hartley $(1994,1996)$ indicated that product development practices such as part reduction and standardization, concurrent engineering, cross-functional teams, vendor management and empowerment, are related to product development cycle times. Concurrent engineering is associated with improvements in product quality and reductions in new product development cycle time and cost through effective communication between the design and manufacturing functions, and an emphasis on cross-functional integration (Chase et al., 1998, Hoedemaker et al., 1999, Standish et al., 1994). Cross-functional teams have been credited by Toyota Motor Corporation with reducing development costs on new car programs by more than 60\% (Chase et al., 1998). Quality function deployment and value analysis/engineering are additional tools used to enhance the product development process, quality function deployment by incorporating customer needs into design specifications, and value analysis/engineering by seeking to meet functional requirements defined by customers while focusing on value added.

\subsection{Just-In-Time Capability (JIT, $\left.\xi_{2}\right)$}

Since the 1980s, JIT has emerged as a significant factor in enhancing competitive advantage. It is based on the notion that simplifying manufacturing processes and reducing variation can result in the elimination of waste. A pioneer in JIT studies, Monden $(1983,1986)$ 
described various JIT practices through careful observation and analysis of Toyota's operations. Key practices included setup time reduction, small lot sizes, process design and standardization, preventive maintenance, product simplification, JIT deliveries, high supplier quality levels, continuous improvement efforts, and quality control. Lee and Ebrahimpour (1984) concluded that top management support of the JIT system, cooperation from the labor force, good process design and effective supplier relationships are also important JIT practices.

The positive impact of JIT on both manufacturing and business performance is largely without question. Gains in inventory performance (e.g., Callen, et al., 2000, Fullerton and McWaters, 2001, Germain and Dröge, 1998, Huson and Nanda, 1995, Nakamura et al., 1998), quality (e.g., Fullerton and McWaters, 2001, Im and Lee, 1989, Lawrence and Hottenstein, 1995, Nakamura et al., 1998), and throughput (e.g., Flynn et al., 1995a, Fullerton and McWaters, 2001, Im and Lee, 1989, Lawrence and Hottenstein, 1995, Nakamura et al., 1998, White et al., 1999) performance have all been consistently observed. Moreover, the adoption of JIT methods has also been shown to positively impact business performance, measured both in financial terms (Callen et al., 2000, Fullerton and McWatters, 2001, Germain and Dröge, 1998, Germain et al., 1996, Huson and Nanda, 1995, Tan, 2001), and market terms (Germain and Dröge, 1998, Germain et al., 1996, Tan, 2001). However, while not doubting the positive impact of JIT, Sakakibara et al. (1997) suggested that JIT's impact on performance is a function of the infrastructure required to support JIT operations, such as a focus on quality management and the integration of the JIT philosophy into a broader strategic framework. The implication is that in and of itself, JIT may not be directly responsible for improvements in performance. 


\subsection{Quality Management Capability (Quality, $\left.\xi_{3}\right)$}

Over the last decade, quality management has emerged as a key driver of organizational performance. Indeed, it was viewed by many organizations as one of their top strategic issues (Malhotra et al., 1994). While quality management has implications for the entire organization, its relevance to the operations function is of particular significance. The operations literature is replete with approaches to managing quality. Efforts to synthesize the various practices into a number of underlying dimensions of quality management (e.g., Ahire et al., 1996, Anderson et al., 1994, 1995, Black and Porter, 1996, Flynn et al., 1995b, Saraph et al., 1989) have resulted in a number of key elements being identified. Leadership and senior management commitment to a quality strategy, and a customer focus are the key drivers of any quality effort. These lay the foundation for efforts to train and empower employees, design products and processes, monitor system performance, and develop relations with suppliers in a way that supports the achievement of quality objectives. Information links the components of the quality system, allowing the organization to recognize whether it is achieving its objectives, and identifying whether it needs to take corrective action to resolve quality system failures. These elements of quality management are the cornerstone of the framework underlying the Malcolm Baldrige National Quality Award (NIST, 2002).

While quality improvement efforts have yielded success (e.g., Easton and Jarrell 1998, Hendricks and Singhal, 1996, 1997), they have not done so uniformly (Grant et al., 1994, Hiam 1993). For many firms, lack of understanding of the relationships between quality practices and outcomes has resulted in initiatives being used in a piecemeal manner or without understanding their impact (Cole 1993, Schaffer and Thomson 1992). Recent studies have however provided greater insight into these relationships and suggest how various practices impact performance. 
For example, customer satisfaction (Anderson et al., 1994, 1995), product quality (Ahire et al., 1996, Dow et al., 1999), as well as broader measures of manufacturing performance (Flynn et al., 1995, Samson and Terziovski, 1999), and business performance (Kannan et al., 1999, Powell, 1995, Tan, 2001) have all been shown to positively correlate with effective management of quality.

\subsection{Acquiring Operations Capability}

The above discussion coupled with observations from the manufacturing capability literature (Roth and Miller, 1992, De Meyer et al., 1989) suggests that a firm's capability in the areas of new product design and development, quality management, and production control/manufacturing systems management, as embodied by JIT, can significantly impact the ability of the operations function to support corporate strategic objectives via improvements in quality, delivery, cost and flexibility. Moreover, these are aspects of a firm's capabilities over which the operations function has significant control. Unlike prior analyses of capability however, the capabilities defined here can be represented by specific actions rather than by objectives. We therefore propose the following:

Hypothesis 1: Operations capability can be defined in terms of three interrelated facets, new product design and development capability, just-in-time capability and quality management capability $\left(\phi_{21}, \phi_{31}\right.$, and $\left.\phi_{32}\right)$.

Each of the facets of operations capability can be operationalized in terms of specific actions. Drawing from the literature, we further propose the following:

Hypothesis 2a: New product design and development capability can be operationalized in terms of an organization's commitment to concurrent engineering, value analysis/value engineering, simplification and standardization of component parts, modular design of parts, and early supplier involvement $\left(\lambda_{11}, \lambda_{21}, \lambda_{31}, \lambda_{41}, \lambda_{51}\right.$, and $\left.\lambda_{61}\right)$. 
Hypothesis 2b: Just-in-time capability can be operationalized in terms of an organization's commitment to reducing setup times and lot sizes, increasing delivery frequencies, reducing inventory to expose manufacturing and scheduling problems and to free up capital, and maintaining process integrity by way of preventive maintenance $\left(\lambda_{72}, \lambda_{82}\right.$, $\lambda_{92}, \lambda_{10,2}, \lambda_{11,2}$, and $\left.\lambda_{12,2}\right)$.

Hypothesis 2c: Quality management capability can be operationalized in terms of an organization's commitment to senior management communicating quality goals to the organization, designing quality into the product, process improvement, maintaining process integrity using statistical process control, training of employees in quality management and control, and empowering operators to correct quality problems $\left(\lambda_{13,3}, \lambda_{14,3}, \lambda_{15,3}, \lambda_{16,3}\right.$, $\lambda_{17,3}$, and $\left.\lambda_{18,3}\right)$.

To test the hypotheses, the following structural equation model of operations capability is proposed (Figure 1).

Insert Figure 1

The literature on new product design and development, just-in-time, and quality management is limited in terms of cross border studies. Most of the extant literature is based on U.S. companies. However studies that have examined non U.S. firms, primarily those in Europe, have yielded similar conclusions regarding the effects of new product design and development, just-in-time, and quality management (e.g. De Meyer et al., 1989). While the specific competitive pressures faced in different regions may vary, how firms respond using their operations function may not. This suggests that the underlying dimensions of operations capability are consistent across borders. Based on this, we propose the following:

Hypothesis 3: The definition of operations capability does not vary between firms in the U.S. and Europe.

To show that a construct is invariant between two samples, it is necessary to show that the items comprising a particular measuring instrument are equivalent between the two groups (i.e., invariance of the measurement models), and that the factorial structure of the instrument is 
also equivalent (i.e., invariance of the structural model). Consistent with accepted methodology for testing factorial invariance of a construct (Jöreskog and Sörbom, 1993, Byrne, 1998), the following hypotheses are therefore proposed as a means of evaluating hypothesis 3 :

Hypothesis 3a: The measurement of the operations capability construct does not vary between firms in the U.S. and Europe in terms of the pattern of factor loadings $(\lambda s)$.

Hypothesis 3b: The measurement of the operations capability construct does not vary between firms in the U.S. and Europe in terms of the pattern of factor correlations $(\phi \mathrm{s})$.

Hypothesis 3c: The measurement of the operations capability construct does not vary between firms in the U.S. and Europe in terms of the pattern of error variances $(\delta \mathrm{s})$.

\subsection{Survey Methodology}

A questionnaire was designed to collect data used to test the proposed hypotheses. The questionnaire used five point Likert scales to ask questions regarding the dimensions of new product design and development, just-in-time, and quality management addressed in the hypotheses. A pretest involving thirty senior supply and materials managers was used to assess content validity of the survey instrument and where necessary, modifications were made to the instrument. The revised questionnaire was mailed to 4,500 managers in the U.S. and 970 in Europe identified from American Production and Inventory Control Society (APICS) and Institute of Supply Management (ISM, formerly the National Association of Purchasing Management) membership lists. Two mailings and one follow-up reminder yielded 411 useable surveys from the U.S. and 116 from Europe. To test for non-response bias, each sample was separated into two groups based on return date, late arriving surveys considered representative of non-respondents (Armstrong and Overton, 1977, Lambert and Harrington, 1990). $t$-tests were carried out on responses to a number of randomly selected survey items, the number of 
employees, and annual sales. No statistically significant differences in mean responses were observed, indicating the absence of non-response bias. Table 1 presents summary details of each sample. While the median number of employees in the European sample is twice that of the U.S. sample, median gross sales are similar (approximately $\$ 120$ million) for both.

Insert Table 1

To ensure that survey items measured the corresponding construct consistently and were free of measurement error, reliability analysis was carried out on each sample using Cronbach's $\alpha$ (Cronbach, 1951, Table 2). Values of $\alpha$ in excess of 0.70 suggested that all scales can be considered reliable (Nunnally, 1988).

Insert Table 2

\subsection{Statistical Analysis}

For each sample, LISREL-SIMPLIS 8.30 (Jöreskog and Sörbom, 1993) was used to analyze the individual factor measurement models as well as the first-order confirmatory factor analysis model. These analyses allow convergent and discriminant validity to be evaluated. Multiple-group analysis was then conducted to investigate whether the three-factor structure would be invariant across the two samples. The test for factorial invariance examines whether a model, when applied to multiple samples, has the same number of latent variables with the same indicators and specification of fixed and free parameters in the matrices of factor loadings, factor intercorrelations, and measurement errors (Bollen, 1989). An overall $\chi^{2}$ test is calculated to measure the fit of the model to both groups (i.e., a test of invariance), and the goodness-of-fit 
index (GFI) (Jöreskog and Sörbom, 1993) calculated for each group to indicate model fit for each group separately.

\subsection{Analysis of Measurement Models}

A structural equation model is reliable only if its parameter values can be estimated (Raykov and Marcoulides, 2000). For this to occur, the model must be identified (Maruyama, 1998, Raykov and Marcoulides, 2000). A necessary condition for identification is that the model must have a positive number of degrees of freedom ${ }^{1}$. To establish the scale for each latent variable in the model, the first regression path in each measurement model was fixed at one. Each construct must therefore have at least four indicators if error covariances are not correlated, to ensure a minimum of one degree of freedom. In this paper, each construct consists of six indicators, thus all the three constructs are over-identified. The maximum likelihood (ML) estimation method was used to estimate parameters in this research (Byrne, 1998).

Tests of hypotheses related to group invariance generally start with scrutiny of the measurement models (Byrne, 1998, Anderson and Gerbing, 1988). Results of analysis of the measurement models are shown in figure 2 and table 3 . The first measurement model analyzed was NPDD for the U.S. sample. While the fit indices indicated good model fit, modification indices suggested early supplier involvement (Q1B) influenced simplification of parts (Q1D). Involving key suppliers early in the product design stage may adversely impact part simplification efforts since suppliers may introduce new technologies and materials that represent a superior alternative to existing parts. Error covariance terms were also included to link standardization of parts (Q1E) with simplification of parts (Q1D) and value

\footnotetext{
${ }^{1}$ Degrees of freedom $=[p(p+1) / 2+$ fixed observed variables $]-$ sum [paths from latent to observed variables, residuals on observed variables, unidirectional and covariance paths, and residuals of structural model], where $p$ is the total number of observed measures (Maruyama, 1998).
} 
analysis/engineering $(\mathrm{Q} 1 \mathrm{~F})$. This is consistent with value analysis/engineering leading to an increased level of part standardization in an attempt to simplify product design and component parts while improving performance. The measurement model was modified accordingly (Figure 2a, standardized parameter values are given).

The NPDD measurement model was analyzed for the European sample using the same set of indicators. Although fit indices indicated the model fit the data well, modification indices suggested concurrent engineering (Q1C) influences early supplier involvement (Q1B) and modular design of parts (Q1A). Concurrent engineering utilizes cross-functional teams that often include key suppliers in new product design and development. The use of modular design is also consistent with concurrent design. As was the case for the U.S. sample, modification indices indicated that value engineering influences part simplification. The modifications were incorporated into the measurement model accordingly (Figure 2b).

The JIT measurement models for the U.S. (Figure 2c) and European (Figure 2d) samples were analyzed separately using the same set of indicators. Both models fit the sample data well (Table 3). For the U.S. sample, reducing setup time (Q2C) was found to influence lot size reductions $(\mathrm{Q} 2 \mathrm{~A})$, preventive maintenance $(\mathrm{Q} 2 \mathrm{C})$, and reducing inventory to expose scheduling and production problems $(\mathrm{Q} 2 \mathrm{~F})$. The underlying premise of the JIT philosophy is that inventory hides scheduling, production and other problems. To lower inventory levels, JIT manufacturers utilize small lot sizes to reduce cycle inventory, but to do so economically, they must drastically reduce setup times. Preventive maintenance is also critical to ensure that equipment and machinery operate smoothly despite frequent setups. Modification indices also suggested that inventory reductions adversely influenced delivery frequency (Q2D), a not uncommon phenomenon. The modifications were added to the measurement model (Figure 2c). 
The quality measurement models for both the U.S. and European samples were also analyzed using the same set of indicators. Modification indices suggested that in both models, communication of quality goals by senior management $(\mathrm{Q} 3 \mathrm{~F})$ influenced employee training in quality (Q3D). Since expenditures on employee training in quality depend largely on the commitment of senior management to supporting quality initiatives, one should expect that where there is a commitment to quality, this will be communicated throughout the organization, and that management will also stress the need to adequately prepare employees. The models were modified accordingly (Figures 2e and f).

Based on Bentler's (1992) recommended fit indices, CFI and NFI, all six measurement models exhibit good fit (Table 3). Indeed, with few exceptions, values of all the commonly used fit indices (CFI, NFI, NNFI, IFI, RFI) exceeded 0.90 and values of $\chi^{2} / \mathrm{df}$ were less than three, further evidence that the models fit the sample data well. Examination of unstandardized solutions of the models revealed all parameter estimates to be both reasonable and statistically significant, and all standard errors to be of acceptable magnitude. The six measurement models thus suggest that with the exception of the error covariance terms for the NPDD and JIT models, the three constructs of interest can be measured by the same set of indicators for both U.S. and European samples. Differences in error covariance terms were however retained and not held invariant in subsequent analyses. A priori knowledge of group differences is critical to the application of invariance-testing procedures (Byrne, 1998).

Insert Figure 2

Insert Table 3 
Consistent with standard invariance analysis practice, a baseline confirmatory factor analysis (CFA) model was established for each sample separately. Each observed variable was allowed to load on only one latent variable. The baseline three-factor operations capability CFA models for the U.S. and European samples are shown in figure 3 (model fit indices are shown in table 3). Model fit indices suggest that both baseline models fit their respective sample data well, indicating that operations capability is appropriately described by the proposed three-factor structure consisting of new product design and development, just-in-time, and quality.

To test hypothesis 3 , the equality of factor structures in the CFA model was tested in a series of multiple-group analyses. There are three sets of parameters in the proposed model shown in figure 1: the eighteen factor loadings $\left(\lambda_{11}\right.$ to $\left.\lambda_{18,3}\right)$ corresponding to the paths from NPDD, JIT and Quality to the indicators; the three correlations ( $\phi_{21}$ to $\phi_{32}$ ) among NPDD, JIT and Quality; and the eighteen error variances $\left(\delta_{1}\right.$ to $\left.\delta_{18}\right)$ of the indicators. The first analysis conducted (Table 4, Model 1) assumed all parameters (factor loadings, correlations and error variances) to be invariant in both groups with the exception of the differences in error covariance terms in the NPDD and JIT measurement models. Fit indices (Table 4) suggested that Model 1 did not fit the data well. A less constrained model (Model 2) was considered which allowed factor loadings to be different for the two samples but retained the invariance of the factor correlations and error variances. Fit indices (Table 4) again suggested the model did not fit the data well. The model was relaxed further by allowing error variances to be different among the two samples, but constrained factor correlations to be invariant (Model 3). Fit indices (Table 4) showed this model fit the data well, suggesting that factor correlations are indeed invariant between the two samples. A final analysis was carried out (Model 4) to test whether in addition to factor correlations, factor loadings are also invariant between the two samples. Factor loadings 
and correlations were held invariant but error variances were allowed to differ between the two samples. This model also fit the data well (Table 4). Thus the conclusion that can be reached is that the only difference between the U.S. and European samples, in addition to the a priori differences in error covariances, is in their error variances. The analysis shows that factor loadings and factor correlations are invariant between the U.S. and European samples.

\begin{tabular}{|c|}
\hline Insert Figure 3 \\
\hline Insert Table 4 \\
\hline
\end{tabular}

\subsection{Discussion}

Results provide support for Hypothesis 1 that from an acquisition standpoint, operations capability can be considered to be a multi factor construct reflecting an organization's focus on new product design and development, just-in-time, and quality efforts. While each factor has been shown in the past to be a significant element in an organization's efforts to leverage its operations function and to create value, until now, the interaction between the factors and their role as elements of an underlying construct has not. This is a significant observation since it demonstrates the multifaceted nature of operations capability. Not only must an organization effectively manage the underlying manufacturing processes it utilizes, it must carefully examine the context in which it uses these processes for it to fully leverage its operations function. In other words, it needs to understand how the operations function creates value from a customer perspective, by focusing on value added in the product design process, designing products in a manner that is consistent with manufacturing abilities, and by developing an infrastructure that supports high quality processes. 
Evidence also exists to support hypotheses 2a-2c regarding the elements of the three components of operations capability. While it is generally accepted that each of the three components is itself multifaceted, with the exception of quality management, little empirical evidence exists to confirm the underlying elements of each. In the case of new product design and development and just-in-time, while considerable case and anecdotal evidence exists to suggest what the underlying elements of each are, corresponding multivariate analysis does not. While not claiming to have identified all underlying elements of new product design or development or just-in-time, this study does suggest what some of the elements might be.

The results also provide support for Hypothesis 3 and the corollary hypotheses $3 \mathrm{a}$ and $3 \mathrm{~b}$, but not hypothesis $3 \mathrm{c}$. This implies that the underlying construct of operations capability is equivalent in both U.S. and European firms. Besides the noted differences in error covariances, the only difference between the two samples is in their error variances, which represent random measurement errors. The result is significant for several reasons. From a methodological perspective, it provides evidence of the proposed construct's validity. While the validity of a construct in different environments cannot be assumed, few studies in the operations literature (e.g., Calantone et al., 1996, Madu et al. 1995, Narasimhan and Jayaram, 1998) have explicitly tested for measurement invariance. Indeed in two of the three recent studies to do so (Madu et al. 1995, Narasimhan and Jayaram, 1998), constructs of interest were found to vary in the different environments examined. From a managerial perspective, the results provide evidence that the operations capability construct as well as its underlying dimensions constitute core sources of competitive advantage that have universal appeal, though the relative impact of each dimension may differ. 
The results have other managerial implications. The identification of the underlying dimensions of operations capability provides management with a diagnostic tool not only for evaluating the effectiveness of the resource deployment process but for increasing the contribution of cross-functional and boundary spanning efforts to the strategic goals of the firm. Knowledge of the dimensions also makes it possible to identify appropriate performance measures and subsequently to evaluate how the resource deployment process impacts performance, the goal being to enhance operations capability and in turn manufacturing and corporate performance.

The study is not without its limitations. Self-reported data was used for all variables of interest. Since cost considerations precluded the use of multiple respondents within an organization, the possibility of respondent bias cannot be ruled out. However, the focus of this study is on theory building rather than theory testing. More extensive testing of the conceptual model is needed to provide additional support for the hypotheses presented. While the foundation for the study is that operations capability is an enabler in achieving strategic objectives, the link between operations capability and performance, a proxy for the achievement of objectives, was not examined. This was not however the objective of this study but represents an opportunity for future work. 


\section{REFERENCES}

Ahire, S. L., Golhar, D. Y., and Waller, M. A., 1996, Development and validation of TQM implementation constructs. Decision Sciences, 27(1), 23-56.

Amit, R., and Shoemaker, P.J.H., 1993, Strategic assets and organizational rent. Strategic Management Journal, 14(1), 33-46.

Anderson, J. C., and Gerbing, D. W., 1988, Structural equation modeling in practice: A review and recommended two-step approach. Psychological Bulletin, 103(3), 411-423.

Anderson, J. C., Rungtusanatham, M., and Schroeder, R. G., 1994, A theory of quality management underlying the Deming method. Academy of Management Review, 19(3), 472509 .

Anderson, J. C., Rungtusanatham, M., Schroeder, R. G., and Devaraj, S., 1995, A path analytic model of a theory of quality management underlying the Deming management method: Preliminary empirical findings. Decision Sciences, 26(5), 637-658.

Armstrong, J. S., and Overton, T. S., 1977, Estimating non-response bias in mail surveys. Journal of Marketing Research, 14(3), 396-402.

Barney, J., 1991, Firm resources and sustained competitive advantage. Journal of Management, 17(1), 99-120.

Bentler, P. M., 1992, On the fit of models to covariances and methodology. Psychological Bulletin, 112(3), 400-404.

Black, S. A., and Porter, L. J., 1996, Identification of the critical factors of TQM. Decision Sciences, 27(1), 1-21.

Bollen, K. A., 1989, Structural equations with latent variables. Wiley, New York.

Byrne, B. M., 1998, Structural equation modeling with Lisrel, Prelis, and Simplis: Basic concepts, applications, and programming. Lawrence Erlbaum Associates, Mahwah.

Calantone, R.J., Song, X.M., and Schmidt, J.M., 1996, Controllable factors of new product success: A cross-national comparison. Marketing Science, 15(4), 341-58.

Callen, J.L., Fader, C., and Krinsky, I., 2000, Just-in-time: A cross sectional plant analysis. International Journal of Production Economics, 63, 277-301.

Chase, R. B., Aquilano, N. J., and Jacobs, F. R., 1998, Production and operations management: Manufacturing and services, $8^{\text {th }}$ Edition. Irwin McGraw-Hill, Burr Ridge.

Cleveland, G., Schroeder, R.G., and Anderson, J.C., 1989, A theory of production competence. Decision Sciences, 20(4), 655-668.

Cole, R.E., 1993, Introduction to the special issue on total quality management. California Management Review, 35, 7-11.

Cool, K. and Schendel, D., 1988, Performance differences among strategic group members. Strategic Management Journal, 9, 207-223.

Copacino, W. C., 1996, Seven supply-chain principles. Traffic Management, 35(1), 60. 
Cronbach, L.J., 1951, Coefficient alpha and the internal structure of tests. Psychometrika, 16, 297-334.

Cronbach, L. J., and Meehl P. E., 1955, Construct validity in psychological tests. Psychological Bulletin, 52, 281-302.

De Meyer, A., Nakane, J., Miller, J.G., and Ferdows, K., 1989, Flexibility: The next competitive battle. The manufacturing futures survey. Strategic Management Journal, 10, 135-144.

Dow, D., Samson, D., and Ford, S., 1999, Exploding the myth: Do all quality management practices contribute to superior quality performance? Production and Operations Management, 8(1), 1-27.

Droge, C., Vickery, S., and Markland, R.E, 1994, Sources and outcomes of competitive advantage: An exploratory study in the furniture industry. Decision Sciences, 25(5/6), 669690.

Easton, G.S. and Jarrell, S.L., 1998, The effects of total quality management on corporate performance: An empirical investigation. Journal Of Business, 71, 15-35.

Ferdows, K., and De Meyer, A., 1990, Lasting improvements in manufacturing performance: In search of a new theory. Journal of Operations Management, 9(2), 168-184.

Flynn, B.B., Sakakibara, S., and Schroeder, R.G., 1995a, Relationship between JIT and TQM: Practices and performance. Academy of Management Journal, 38(3), 1325-1360.

Flynn, B. B., Schroeder, R. G., and Sakakibara, S., 1995b, The impact of quality management practices on performance and competitive advantage. Decision Sciences, 26(5), 659-691.

Fullerton, R.R., and McWatters, C.S., 2001, The production performance benefits from JIT implementation. Journal of Operations Management, 19, 81-96.

Germain, R., and Dröge, C., 1998, The context, organizational design, and performance of JIT versus non JIT buying firms. International Journal of Purchasing and Materials Management, 34(2), 12-18.

Germain, R., Dröge, C., and Spears, N., 1996, The implications of just-in-time for logistics organization management and performance. Journal of Business Logistics, 17(2), 19-34.

Grant, R.M., 1991, The resource-based theory of competitive advantage: Implications for strategy formulation. California Management Review, 33(3), 114-135.

Grant, R. M., Shani, R., and Krishnan, R., 1994, TQM's challenge to management theory and practice. Sloan Management Review, 35(2), 25-35.

Griffin, A., 1997, Modeling and measuring product development cycle time across industries. Journal of Engineering and Technology Management, 14(1), 1-24.

Hammer, M. and Champy, J., 1993, Reengineering the Corporation: A Manifesto for Business Revolution. Harper Business, New York.

Hayes, R.H., Wheelwright, S. and Clark, K.B., 1988, Dynamic manufacturing. The Free Press, New York.

Hayes, R.H., and Pisano, G.P., 1996, Manufacturing strategy: At the intersection of two paradigm shifts. Production and Operations Management, 5(1), 25-41. 
Hendricks, K. B., and Singhal, V.R., 1997, Does implementing an effective TQM program actually improve operating performance? Empirical evidence from firms that have won quality awards. Management Science, 43, 1258-1274.

Hendricks, K.B., and Singhal, V.R., 1996, Quality awards and the market value of the firm: An empirical investigation. Management Science, 42, 415-436.

Hiam, A., 1993, Does quality work? A review of relevant studies. The Conference Board, New York.

Hoedemaker, G. M., Blackburn, J. D., and Van Wassenhove, L. N., 1999, Limits to concurrency. Decision Sciences, 30(1), 1-18.

Huson, M., and Nanda, D., 1995, The impact of just-in-time manufacturing on firm performance in the U.S. Journal of Operations Management, 12, 297-310.

Im, J.H., and Lee, S.M., 1989, Implementation of just-in-time systems in U.S. manufacturing firms. International Journal of Operations and Production Management, 9(1), 5-14.

Jöreskog, K. G., and Sörbom, D., 1993, LISREL8: Structural equation modeling with the SIMPLIS command language. Lawrence Erlbaum Associates, Hillsdale.

Kannan, V.R., Tan, K.C., Handfield, R.B., and Ghosh, S., 1999, Tools and techniques of quality management: An empirical investigation of their impact on performance. Quality Management Journal, 6(3), 34-49.

Lambert, D. M., and Harrington, T. C., 1990, Measuring non-response bias in mail surveys. Journal of Business Logistics, 11(2), 5-25.

Lawless, M.W., Bergh, D.D., and Wilsted, W.D., 1989, Performance variations among strategic group members: An examination of individual firm capability. Journal of Management, 15, 649-661.

Lawrence, J.J., and Hottenstein, M.P., 1995, The relationship between JIT manufacturing and performance in Mexican plants affiliated with U.S. companies. Journal of Operations Management, 13, 3-18.

Lee, S. M., and Ebrahimpour, M., 1984, Just-In-Time production system: Some requirements for implementation. International Journal of Operations and Production Management, 4(4), 315.

Leong, G.K., Snyder, D.L., and Ward, P.T., 1990, Research in the process and content of manufacturing strategy. OMEGA: International Journal of Management Science, 18(2), 109122.

Littler, D., Leverick. F., and Bruce, M., 1995, Factors affecting the process of collaborative product development: a study of UK manufacturers of information and communications technology products. Journal of Production and Innovation Management, 12(1), 16-32.

Madu, C.N., Kuei, C., and Lin, C., 1995, A comparative analysis of quality practice in manufacturing firms in the US and Taiwan. Decision Sciences, 26(5), 621-635.

Malhotra, M. D., Steele, D. C., and Grover, V., 1994, Important strategic and tactical manufacturing issues in the 1990s. Decision Sciences, 25(2), 189-214. 
Maruyama, G. M., 1998, Basics of structural equation modeling. Sage Publications, Thousand Oaks.

Mason, T., 1996, Getting your suppliers on the team. Logistics Focus, 4(1), 10-12.

Monden, Y., 1983, Toyota production systems: Practical approach to production management. Institute of Industrial Engineers, Norcross.

Monden, Y., 1986, Applying Just-In-Time. Institute of Industrial Engineers, Norcross.

Nakamura, M., Sakakibara, S., and Schroeder, R., 1998, Adoption of just-in-time manufacturing at U.S. and Japanese owned plants: Some empirical evidence. IEEE Transactions on Engineering Management, 45(3), 230-240.

Narasimhan, R.N., and Jayaram, J., 1998, An empirical investigation of the antecedents and consequents of manufacturing goal achievement in North American, European, and Pan Pacific firms. Journal of Operations Management, 16, 159-176.

National Institute of Standards and Technology, 2002, Malcolm Baldrige National Quality Award 2002 criteria for performance excellence. Gaithersburg.

Noble, M.A., 1995, Manufacturing strategy: Testing the cumulative model in a multiple country context. Decision Sciences, 26(5), 693-720.

Nunnally, J., 1988, Psychometric Theory. McGraw-Hill, New York.

Peteraf, M.A., 1993, The cornerstones of competitive advantage: A resource-based view. Strategic Management Journal, 14(3), 179-191.

Powell, T., 1995, Total quality management as competitive advantage: A review and empirical study. Strategic Management Journal, 16, 15-37.

Ragatz, G. L., Handfield, R. B., and Scannell, T. V., 1997, Success factors for integrating suppliers into new product development. Journal of Production and Innovation Management, 14(3), 190-202.

Raykov, T., and Marcoulides, G. A., 2000, A first course in structural equation modeling. Lawrence Erlbaum Associates, Mahwah.

Reise, S. P., Widaman, K. F., and Pugh, R. H., 1993, Confirmatory factor analysis and item response theory: Two approaches for exploring measurement invariance. Psychological Bulletin, 114, 552-566.

Roth, A.V., and Miller, J.G., 1992, Success factors in manufacturing. Business Horizons, JulyAugust, 73-81.

Safizadeh, M.H., Ritzman, L.P., and Mallick, D., 2000, Revisiting alternative theoretical paradigms in manufacturing strategy. Production and Operations Management, 9(2), 111127.

Sakakibara, S., Flynn, B.B., Schroeder, R.G., and Morris, W.T., 1997, The Impact of just-in-time manufacturing and its infrastructure on manufacturing performance. Management Science, 43(9), 1246-1257.

Samson, D. and Terziovski, M., 1999, The relationship between total quality management practices and operational performance. Journal of Operations Management, 17, 393-409. 
Saraph, J. V., Benson, P. G., and Schroeder, R. G., 1989, An instrument for measuring the critical factors of quality management. Decision Sciences, 20(4), 810-829.

Schaffer, R., and Thomson, H., 1992, Successful change programs begin with results. Harvard Business Review, 70(1), 80-89.

Schonberger, R. J., 1986, World class manufacturing: The lessons of simplicity applied. The Free Press, New York.

Standish, R., Jones, R., Sumpter, C., and Sharp, J., 1994, Shortening the new product introduction cycle through electronic data transfer. International Journal of Production Economics, 34(3), 347-357.

Tan, K.C., 2001, A structural equation model of new product design and development. Decision Sciences, 32(2), 195-226.

Vickery, S.K., Droge, C., and Markland, R.E., 1993, Production competence and business strategy: Do they affect business performance? Decision Sciences, 24(2), 435-455.

White, R.E., Pearson, J.N., and Wilson, J.R., 1999, JIT manufacturing: A survey of implementations in small and large U.S. manufacturers. Management Science, 45(1), 1-15.

Zirger, B. J., and Hartley, J. L., 1994, A conceptual model of product development cycle time. Journal of Engineering Technology Management, 11(3/4), 229-251.

Zirger, B. J., and Hartley, J. L., 1996, The effect of accelerated techniques on product development time. IEEE Transactions in Engineering Management, 43(2), 143-152. 
Table 1: Respondents' Profile

\begin{tabular}{|l|r|r|}
\hline \multicolumn{1}{|c|}{ DESCRIPTION } & \multicolumn{1}{|c|}{ U.S. } & \multicolumn{1}{c|}{ EUROPE } \\
\hline \hline Number of Respondents Contacted & 4,500 & 970 \\
Number of Usable Surveys Received & 411 & 116 \\
Number of Employees (including part-time employees) & & \\
Mean & 6,831 & 13,857 \\
Median & 500 & 1,000 \\
Minimum & 3 & 5 \\
Maximum & 300,000 & 240,000 \\
Annual Gross Sales in U.S. \$ & & \\
Mean & $\$ 1.7$ billion & $\$ 2.8$ billion \\
Median & $\$ 124$ million & $\$ 120$ million \\
Minimum & $\$ 5,000$ & $\$ 550$ \\
Maximum & $\$ 59$ billion & $\$ 30$ billion \\
\hline \hline
\end{tabular}

Table 2: Reliability Analysis - Cronbach's $\alpha$

\begin{tabular}{|l||c||c|c||}
\hline \multicolumn{1}{|c||}{ LATENT VARIABLE } & \multirow{2}{*}{ \# OF ITEMS } & \multicolumn{2}{c|}{ CRONBACH'S $\alpha$} \\
& & U.S. & EUROPE \\
\hline \hline New Product Design \& Development & 6 & 0.9125 & 0.8725 \\
\hline Just-In-Time & 6 & 0.8691 & 0.8768 \\
\hline Quality & 6 & 0.8781 & 0.7844 \\
\hline
\end{tabular}

Table 3: Measurement Models and Confirmatory Factor Analysis Fit Indices

\begin{tabular}{|l|cccccccc||}
\hline \multicolumn{1}{|c|}{ MODELS } & $\chi^{2}$ & $\mathrm{df}$ & $\chi^{2} / \mathrm{df}$ & NFI & NNFI & CFI & IFI & RFI \\
\hline \hline NPDD - U.S. & 17.02 & 6 & 2.84 & 0.99 & 0.98 & 0.99 & 0.99 & 0.97 \\
\hline NPDD - Europe & 8.28 & 6 & 1.38 & 0.98 & 0.98 & 0.99 & 0.99 & 0.94 \\
\hline JIT - U.S. & 8.88 & 5 & 1.78 & 0.99 & 0.99 & 1.00 & 1.00 & 0.98 \\
\hline JIT - Europe & 18.76 & 9 & 2.08 & 0.94 & 0.94 & 0.97 & 0.97 & 0.90 \\
\hline QLT - U.S. & 20.44 & 8 & 2.56 & 0.98 & 0.98 & 0.99 & 0.99 & 0.97 \\
\hline QLT - Europe & 18.32 & 8 & 2.29 & 0.90 & 0.88 & 0.94 & 0.94 & 0.82 \\
\hline CFA - U.S. & 353.48 & 124 & 2.85 & 0.93 & 0.94 & 0.95 & 0.95 & 0.91 \\
\hline CFA - Europe & 189.61 & 124 & 1.53 & 0.82 & 0.89 & 0.91 & 0.91 & 0.78 \\
\hline
\end{tabular}


Table 4: Summary of Tests for Invariance of Operations Capability

\begin{tabular}{||l|cccccccc||}
\hline \multicolumn{1}{|c|}{ COMPETING MODELS } & $\alpha^{2}$ & $\mathrm{df}$ & $\alpha^{2} / \mathrm{df}$ & NFI & NNFI & CFI & IFI & RFI \\
\hline $\begin{array}{l}\text { Model 1 with factor loadings, } \\
\text { factor correlations, and error } \\
\text { variances held invariant }\end{array}$ & 1241.3 & 288 & 4.31 & 0.84 & 0.85 & 0.86 & 0.86 & 0.83 \\
\hline $\begin{array}{l}\text { Model 2 with factor correlations } \\
\text { and error variances held invariant }\end{array}$ & 1105.1 & 273 & 4.05 & 0.84 & 0.85 & 0.87 & 0.87 & 0.82 \\
\hline $\begin{array}{l}\text { Model 3 with factor correlations } \\
\text { held invariant }\end{array}$ & 792.6 & 255 & 3.11 & 0.91 & 0.92 & 0.94 & 0.94 & 0.90 \\
\hline $\begin{array}{l}\text { Model 4 with factor loadings and } \\
\text { factor correlations held invariant }\end{array}$ & 934.0 & 270 & 3.46 & 0.90 & 0.92 & 0.93 & 0.93 & 0.89 \\
\hline
\end{tabular}




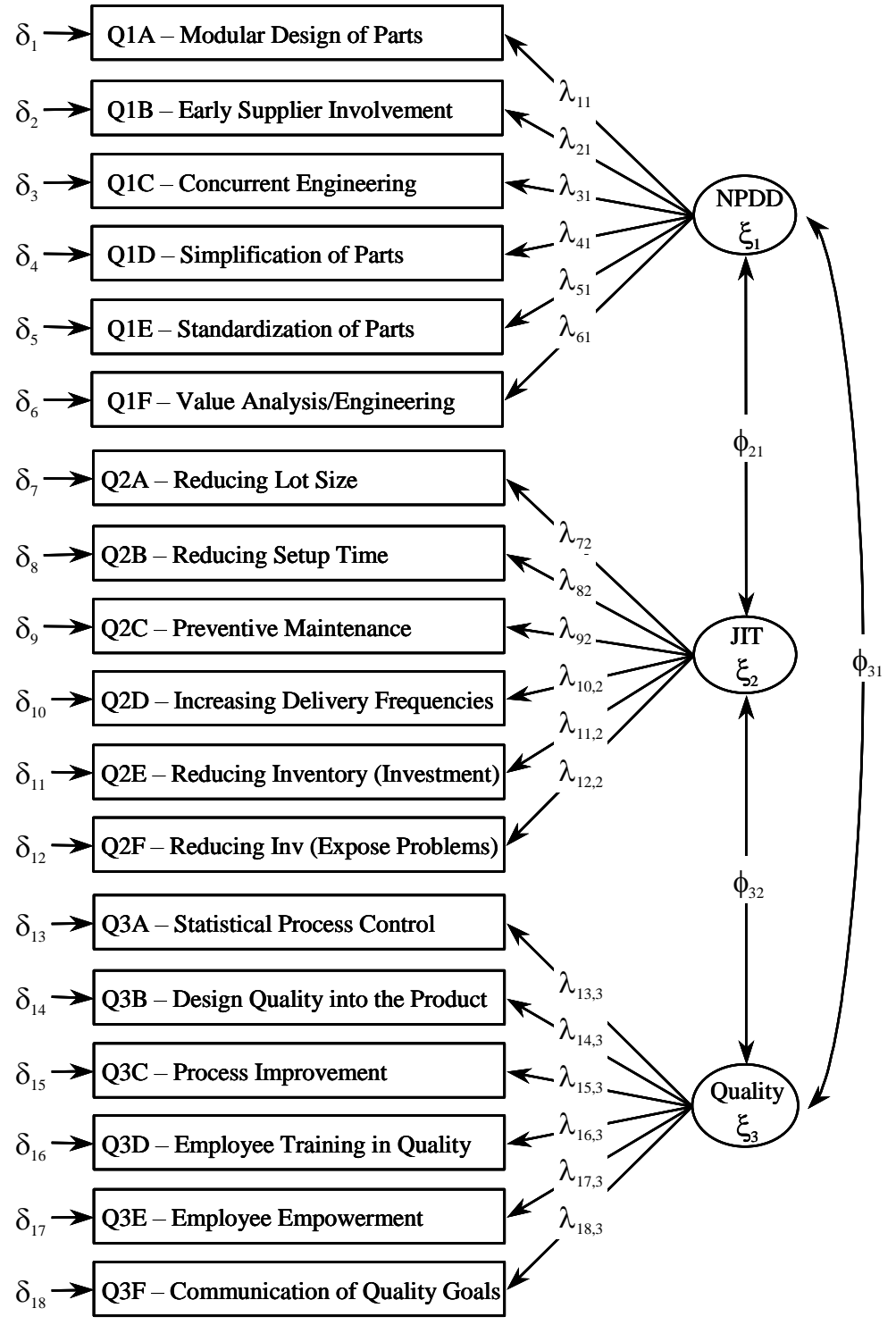

Figure 1: Proposed Three-Factor Operations Capability Model 


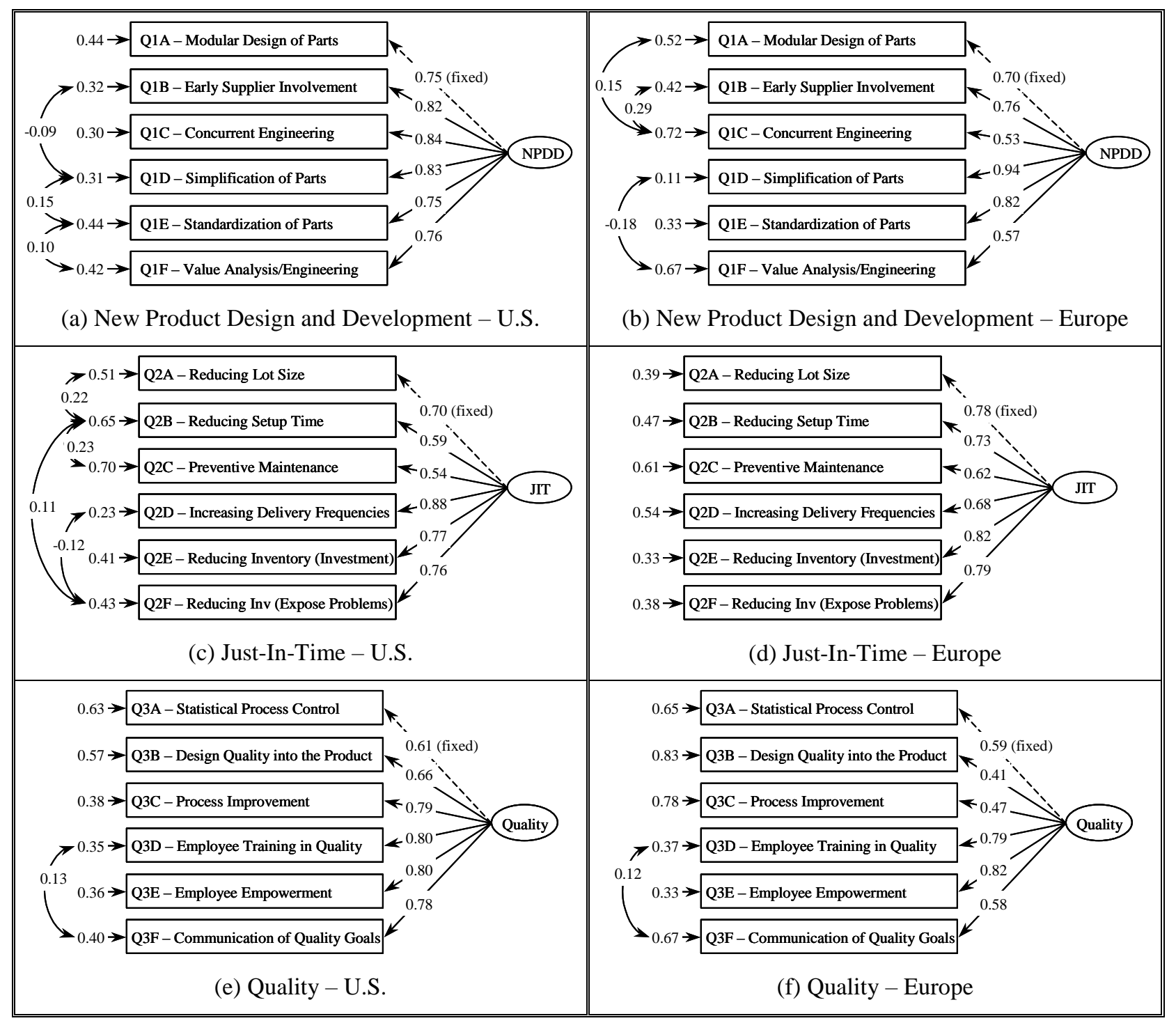

Figure 2: Measurement Models 


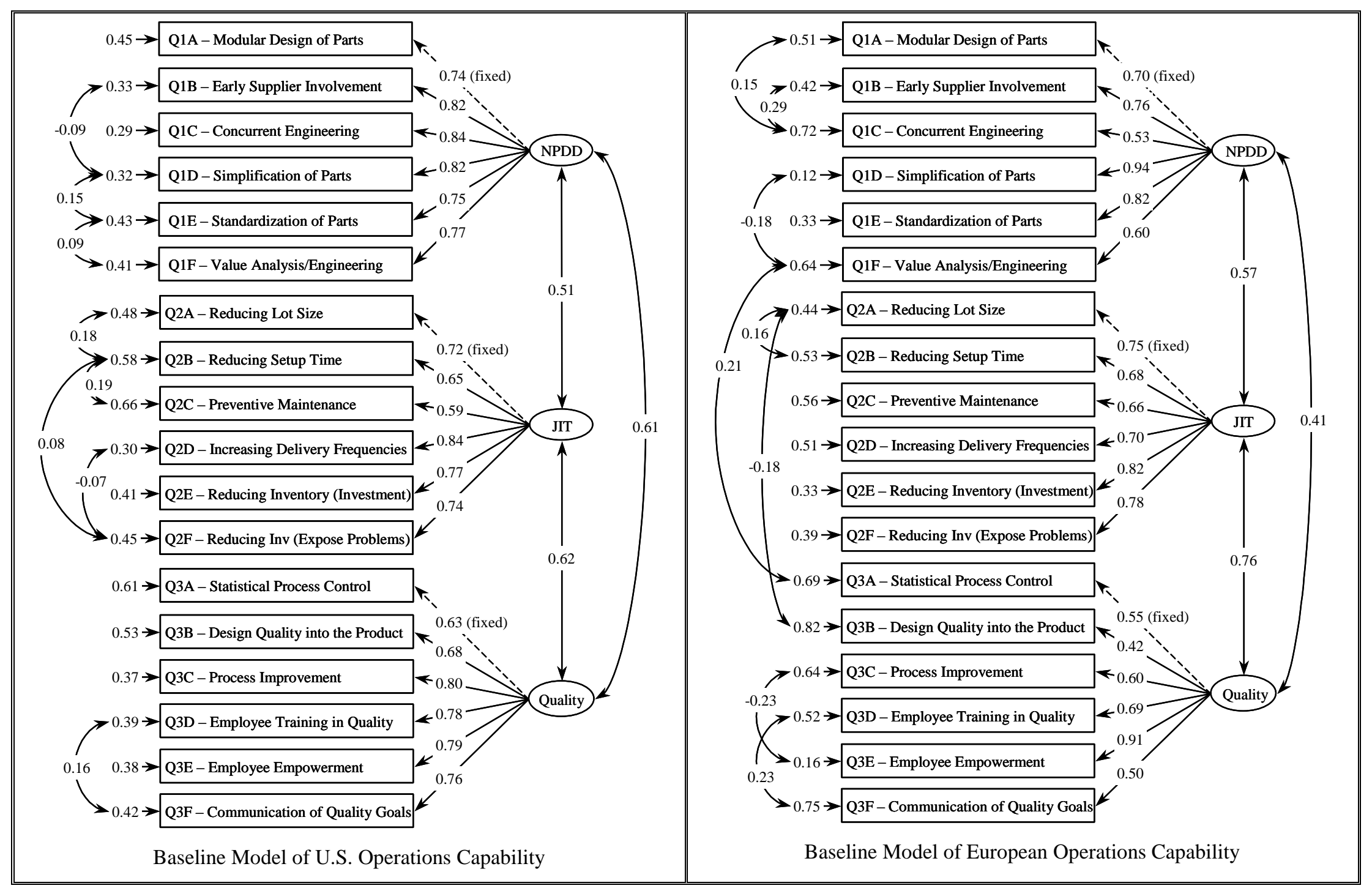

Figure 3: Baseline Models of Operations Capability 